\title{
THEORETICAL AND EXPERIMENTAL HEAT TRANSFER ANALYSIS OF A FLAT PLATE COLLECTOR FOR A SOLAR THERMAL WATER PUMP
}

\author{
A. A. El-Haroun \\ Mechanical Power Eng. Dept., Faculty of Engineering, Minoufiya University, Egypt \\ E-mail:ah81256@yahoo.com,Fax:002048235695.
}

\begin{abstract}
A solar thermal water pump using a flat-plate collector is described. Two working fluids, Ether and Chloroform, which have low boiling points, are used in this pump. Heat-transfer analysis has been carried out for this system taking the majority of all heat losses into account. Variations in temperature and pressure of working fluids in the collection system with time are predicted. The temperature and pressure of working fluids as well as the temperature of collector plate are measured and compared with the predicted values. Variations in collector efficiency with time are discussed.
\end{abstract}

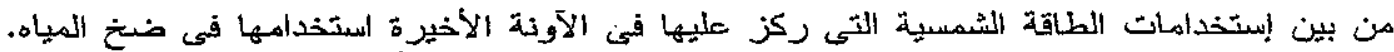

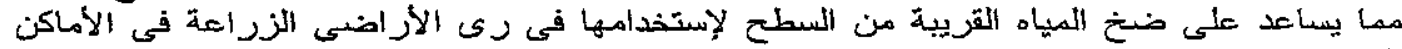

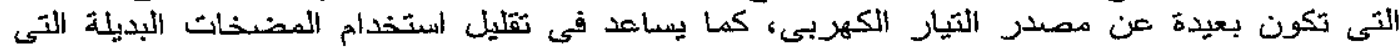

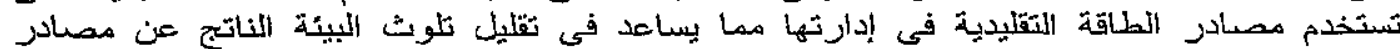

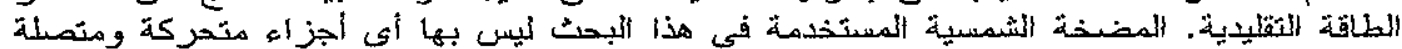

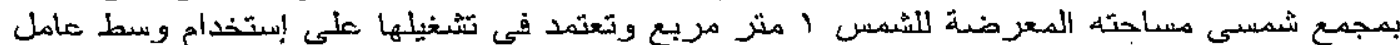

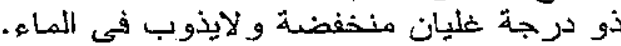

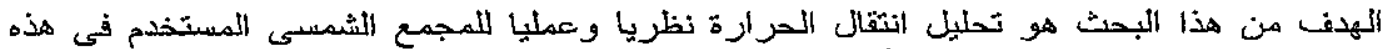

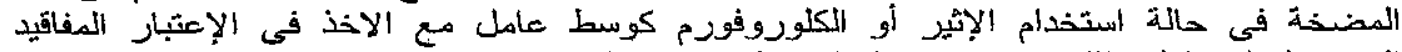

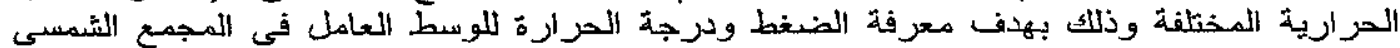

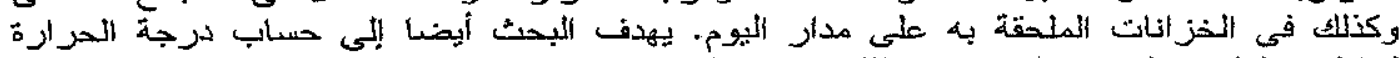

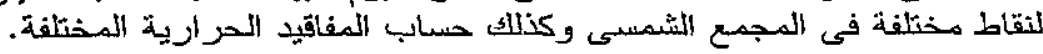
ومن أهم نتائج هذا البحثث مايلى الجيع:

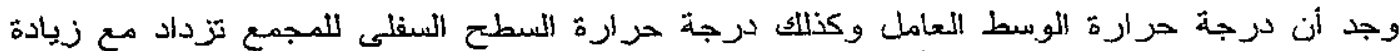

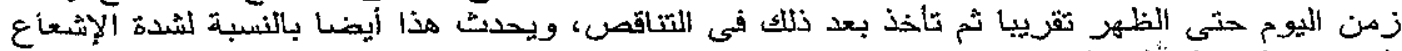
الشسىى السطاقط على المجمع:

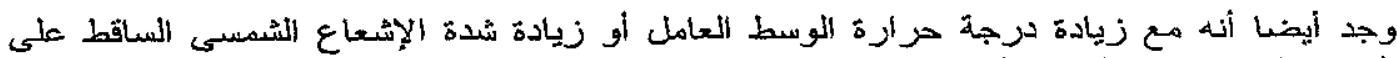

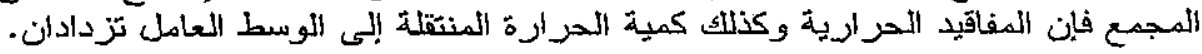

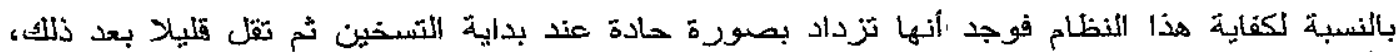

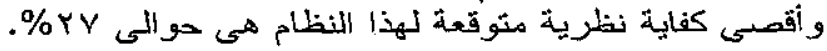

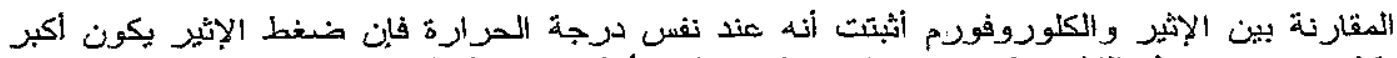

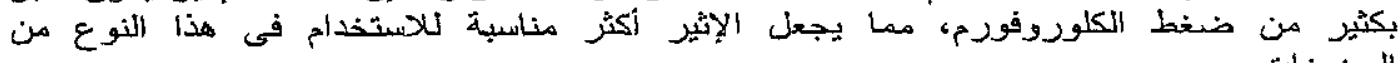

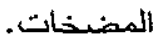

أظهرث القياسات المحلية التىى أجريث على هذه المضذة أن الاختلاف بين النتائج العملية والنظرية معقول.

Keywords Renewable energy, Solar energy, Solar pump, Flat plate collector, Water pumping. 


\section{A. A. El-Haroun, "Theoretical and Experimental Heat Transfer Analysis of a Flat Plate Collector ..."}

\section{INTRODUCTION}

The pump discussed in this work is an unconventional one, which operates using the vapour of a low boiling point liquid (Diethyl Ether or Chloroform) generated by a flat plate collector. These types of pumps have attracted considerable attention since the beginning of the Twentieth century. This unconventional pump can be used particularly in rural areas for irrigation purposes.

Various types of small solar thermal water pumps are discussed in [1]. The performance of some different types of solar thermal water pumps is studied experimentally and theoretically at different discharge heads and for different working fluids in [2], [3], [4], [5], [6], and [7].

Figure 1 shows the schematic of solar thermal water pump considered in this work. The pump consists of the following components: (i) flat plate solar collector having an exposed area of $1 \mathrm{~m}^{2}$ coupled to an insulated tank $\mathrm{S}$, both containing working fluid in liquid condition; (ii) insulated storage tank $\mathrm{N}$, which stores working fluid vapour; (iii) insulated vessel $A$, completely filled with water initially; (iv) uninsulated vessel $B$, initially containing air and (v) vessel $C$, immersed in the well water.

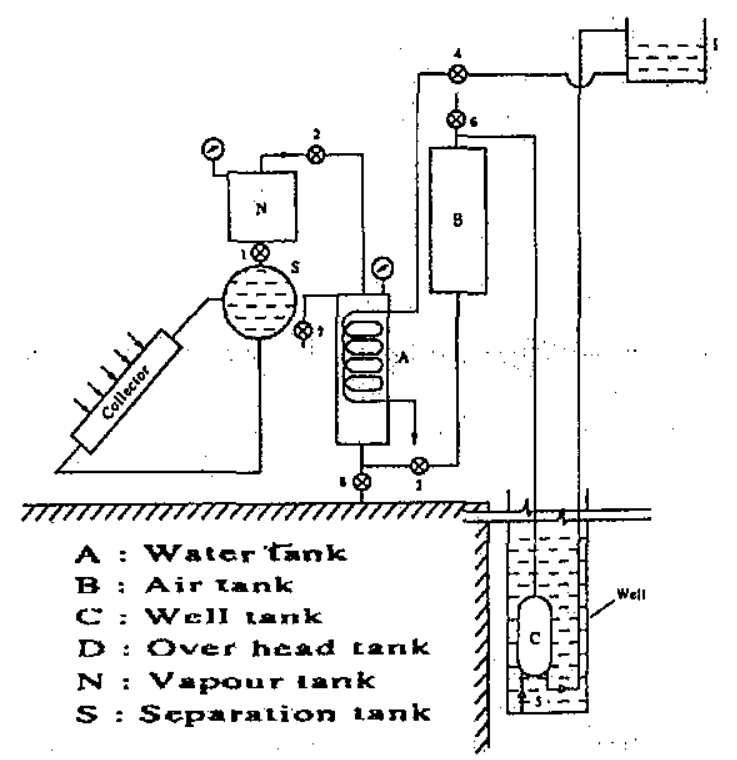

Figure 1 Schematic of the solar thermal water pump

The choice of the working fluid depends to a great extent on the boiling point and its miscibility with water. Diethyl Ether and Chloroform are chosen as two working fluids in this work. They are immiscible with water and have low boiling points, 34.43 and $61.13{ }^{\circ} \mathrm{C}$ respectively. Their chemical formulas are $\mathrm{C}_{4} \mathrm{H}_{10} \mathrm{O}$ and $\mathrm{CHCl}_{3}$ respectively [8].

Liquid Ether or Chioroform is sited in motion by thermosiphon action through solar heating in the flatplate collector. The saturated vapour separating in tank $\mathrm{S}$ is stored in the vapour-storage tank $N$. When the pressure in tank $\mathrm{N}$ reaches a predetermined value, it is isolated from tank $S$ by closing valve 1 . Valves 2 and 3 are simultaneously opened so that some vapour from $\mathrm{N}$ travels quickly to vessel $A$, which initially contains water at atmospheric conditions. As a consequence, water in $\operatorname{tank} A$ is displaced into $\operatorname{tank} B$, which initially contains air at atmospheric conditions. The rising column of water in B compresses the air in it and the compressed air in turn pushes the water in vessel $C$ (which is immersed in the well) to the overhead tank D. At the end of pumping, valve 2 is closed, valve 1 is opened and water from the overhead tank D is allowed to flow through the cooling coils in vessel $A$ to accelerate the condensation of working fluid vapour in $\operatorname{tank} A$. Because of condensation, the pressure in vessel $A$ decreases, as a result of which the water in vessel $B$ returns to vessel $A$. During this period, the pressure of air in vessel $B$ returns to its initial value. Consequently, the well water is sucked into vessel $C$ through the oneway valve 5 . During the condensation and suction stroke the working fluid in the collection system is heated up until the vapour is required for the next pumping operation. One cycle of operation is thus complete and the pump is now ready for the next cycle.

In this work, heat transfer analysis of a flat plate collector in the above described solar thermal water pump is carried out theoretically and experimentally. Two different situations were considered: one with Ether as working fluid and the other when Choloroform is used instead.

\section{HEAT TRANSFER ANALYSIS}

Initially, the system is filled with $\mathrm{m} \mathrm{kg}$ working fluid at the ambient temperature $t_{a}$. Valve 1 is kept open so that the vapour in $\mathrm{N}$ and the liquid in the collector are in equilibrium. Thus, the system considered is a mixture of liquid and vapour at a dryness fraction, which can be calculated at any instant.

The collector analysis is aimed at predicting the temperature and pressure of working fluid as a function of time for different days.

\section{Evaluation of Energy Available from the Collector}

The total radiation intensity on a horizontal plane is assumed to vary sinusoidally from sunrise to sunset according to

$$
I_{h}=I_{\max } \sin [\pi \theta / l]
$$

Where $I_{\max }$ is the maximum intensity of solar radiation occurring at solar noon, $l$ the length of the day in hours and $\theta$ the difference between time of day at a given instant and the sunrise time in hours. Assuming that the diffuse radiation intensity on the horizontal $I_{d}$ is $15 \%$ of the total radiation intensity, then the total intensity of radiation on an inclined surface $I_{i}$ is obtained from 


\section{A. A. El-Haroun, "Theoretical and Experimental Heat Transfer Analysis of a Flat Plate Collector ..."}

$I_{i}=\left(I_{h}-I_{d}\right)\left(\cos \theta_{i} / \cos \theta_{h}\right)+I_{d}(1+\cos \beta) / 2$

where $\theta_{i}$ is the incident angle on the inclined collector, $\theta_{h}$ is the incident angle on the horizontal surface and $\beta$ is the inclination of the collector to the horizontal.

$\theta_{i}=\cos ^{-1}[\cos (L-\beta) \cos \delta \cos h+\sin L \sin \delta]$

$\theta_{h}=\cos ^{-1}[\cos L \cos \delta \cos h+\sin L \sin \delta]$

where $L$ is altitude, $\delta$ is declination and $h$ is the hour angle.

The overall heat loss coefficient, in $\mathrm{W} / \mathrm{m}^{2} \mathrm{~K}$, of a single glazed collector can be obtained from the following relation [6]

$U_{I}=5.5+0.024 t_{p}$

where $t_{p}$ is the plate temperature in ${ }^{\circ} \mathrm{C}$. The absorbed energy per unit area of the collector can be estimated as

$d Q=\left[I_{i}(\tau \alpha)-U_{l}\left(t_{p}-t_{a}\right)\right] d \theta$

where $\alpha$ is the absorptivity of the black painted absorber plate, taken as $0.9 . \tau$ is the transmissivity of the collector glazing, taken as 0.88 [6] and $d \theta$ is the time interval.

The heat transfer to the fluid from the wall during a small interval $d \theta$ is

$d Q_{s}=h_{i} A_{t}\left(t_{w}-t_{s}\right) d \theta / A_{c}$

where $h_{i}$ is the convective heat coefficient between tube wall and the liquid, $A_{t}$ is the inside area of the collector tubes, $t_{\mathrm{w}}$ is the wall temperature of the collector tubes, $t_{s}$ is working fluid temperature in the collector and $\mathrm{A}_{\mathrm{c}}$ is the collector area.

For natural convection horizontal tube with a wall temperature increasing at a uniform rate

$N u=1.181(G r \operatorname{Pr})^{0.214}$

The absorbed energy per unit area of the collector can be estimated also as

$d Q=C_{1} d t_{p}+C_{2} d t_{w}+d Q$

where $C_{1} d_{p}$ is the increase in energy of the flat plate and $C_{2} \mathrm{dt}_{w}$ is the increase in energy of the risers, headers, insulation and glazing in the collector.

The heat conducted from the plate to the riser-tube wall through the bond between them is equal to the sum of the increase in energy of the collector components and the heat transfer to working fluid in the collection system. Therefore,

$\|\left(t_{p}+d t_{p}\right)-\left(t_{w}+d t_{w}\right) C_{b} d \theta=C_{2} d t_{w}+d Q_{s}$ where $\mathrm{C}_{\mathrm{b}}$ is the bond conductance.

For assumed initial values of $t_{p}, t_{w}$ and $t_{s}$ the above equations can be solved together to determine the values of $\mathrm{dt}_{\mathrm{p}}, \mathrm{dt}_{\mathrm{w}}$ and $\mathrm{dQ}_{\mathrm{s}}$

\section{Evaluation of Working Fluid Temperature and Pressure}

The heat transfer to the fluid from the wall $d_{Q_{s}}$ during a small interval $d \theta$ is equal to the difference in internal energy of working fluid, the increase in the heat capacitances of tanks $\mathrm{S}$ and $\mathrm{N}$ along with their insulations and heat losses $\mathrm{dQ}_{1}$ through tanks $\mathrm{S}$ and $\mathrm{N}$. It is assumed that the wall of tanks $\mathrm{S}$ and $\mathrm{N}$ are at the same temperature of working fluid, whereas the insulation is at the average of wall temperature and the outside temperature $t_{0}$. Therefore the rise in temperature of working fluid in interval $\mathrm{d} \theta$ can be obtained from the following relation

$d Q_{s}=\left(U_{f}-U_{i}\right)+C_{3 w}\left(t_{s f}-t_{s}\right)+$
$C_{3 i}\left[\left(t_{s f}+t_{o f}\right) / 2-\left(t_{s}+t_{o}\right) / 2\right]+d Q$

where $\mathrm{C}_{3 \mathrm{w}}$ and $\mathrm{C}_{3 i}$ are the capacitances of tanks $\mathrm{S}$ and $\mathrm{N}$ and their insulation respectively, whereas $t_{s}$ and $t_{s f}$ are the temperatures of working fluid at the beginning and end of interval $d \theta$ respectively. The conduction and convection losses from tanks $\mathrm{S}$ and $\mathrm{N}$ are calculated according to the technique used in [6]. Equation 8 is solved by trial and error to obtain the value of $t_{s f}$ with an accepted error less than $10^{-7}$. The rise in working fluid temperature is then

$d t_{s}=t_{s f}-t_{s}$

For the next interval $d \theta, t_{s}, t_{w}$ and $t_{p}$ are all reset after accounting for their changes during the previous time interval $d \theta$. This evaluation is continued for the entire period of heating. The analysis has been done for two different cases, namely, (i) when Diethyl Ether is used as working fluid and (ii) by using Chloroform as working fluid.

The saturation pressure of Diethyl Ether at any temperature is

$P=15.339+3.275 t-0.015 t^{2}+4.856 \times 10^{-4} t^{3}$

whereas for Chloroform it is

$P=-74.386+3.536 t-0.033 t^{2}+3.7 \times 10^{4} t^{3}$

where $t$ is in ${ }^{\circ} \mathrm{C}$ and $\mathrm{P}$ in $\mathrm{kPa}$.

\section{EXPERIMENTAL STUDIES}

A solar thermal water pump was designed, manufactured and tested in the energy laboratory. The pump was coupled to a flat plate collector with an exposed area of $1 \mathrm{~m}^{2}$. A calibrated Bourdon pressure gauge was mounted on the vapour storage 


\section{A. A. El-Haroun, "Theoretical and Experimental Heat Transfer Analysis of a Flat Plate Collector ..."}

tank $\mathrm{N}$ to measure the pressure of working fluid at any instant. Four calibrated copper-constantan thermocouples are used for measuring the temperatures at collector inlet, collector outlet and collector plate as well as for measuring the temperature of working fluid in tank $\mathrm{N}$ at any instant. The collector and the separation tank $S$ are initially filled with working fluid in liquid phase. The vapour storage $\operatorname{tank} N$ is then brought in communication with the tank $S$ so that the working fluid vapour separating from tank $S$ is stored in tank $N$. The working fluid in the system was just heated continuously by thermosiphon action. The temperature and pressure at the above indicated locations in the systems were measured for different days from 9 to $160^{\prime}$ clock for the two working fluids.

\section{RESULTS AND DISCUSSION}

Figure 2 shows the predicted variation of solar radiation intensity with time in the location of this study for different summer days. The solar radiation intensity varies sinusoidal with time and takes its maximum value at solar noon.

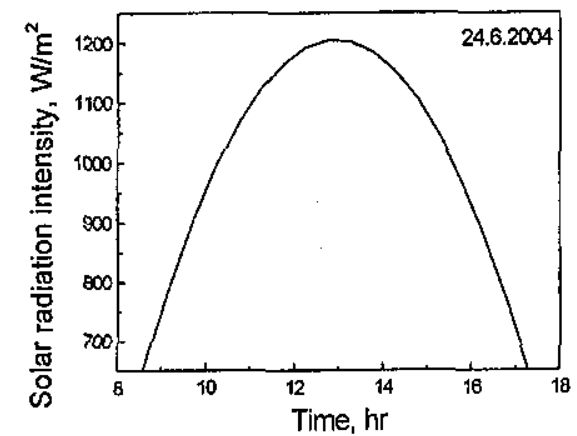

(a)

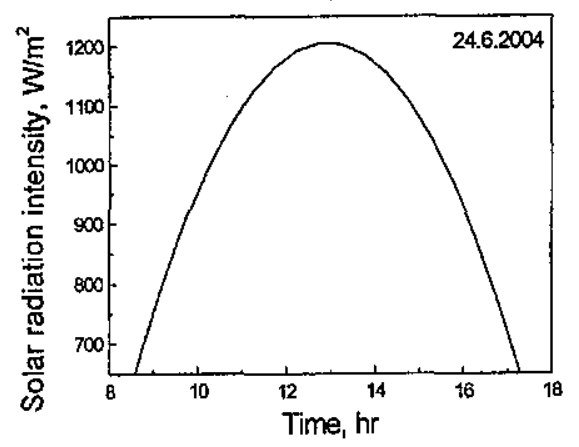

(b)

Figure 2 Variation of solar radiation intensity with time

Figure 3 illustrates the predicted change in working fluid (Ether) and collector plate temperatures with time. The temperature of Ether in the collecting system as well as the temperature of collector plate varies sinusoidal with time. The maximum values occur at about $130^{\circ}$ 'clock. Values of 55 and $84^{\circ} \mathrm{c}$ are predicted for Ether and collector plate temperatures respectively for this day.

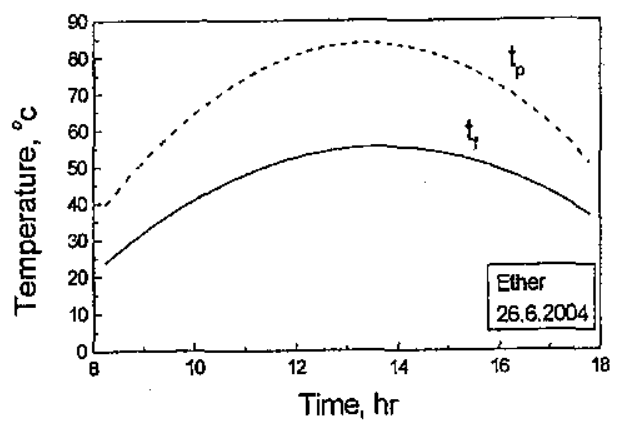

Figure 3 Variation of working fluid and collector plate temperatures with time

The variation of heat absorbed per unit area of collector, heat losses from tanks $\mathrm{S}, \mathrm{N}$ and heat transferred to working fluid with time is shown in Fig. 4. The behavior of these parameters before solar noon differs from their behavior after solar noon. They increase till solar noon then they decrease. It is also found that heat absorbed per unit area of collector is at the top of other two parameters before solar noon. After solar noon, heat losses from tanks $\mathrm{S}, \mathrm{N}$ and heat transferred to working fluid are found to be greater than heat absorbed per unit area of collector. This is because a heat conserved in tube walls, walls of tanks $S, N$ as well as heat conserved in insulation will flow to working fluid and to the surroundings.

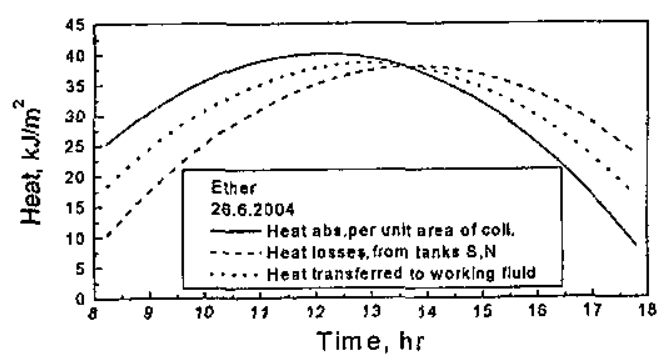

Figure 4 Predicted values of heat absorbed per unit area of collector, heat losses from tanks $\mathrm{S}, \mathrm{N}$ and heat transferred to working fluid

Figure 5 presents the change of heat losses from tanks $\mathrm{S}$ and $\mathrm{N}$ with the working fluid temperature. The heat losses increase with the rise in working fluid temperature. This is because of the rise in the temperature difference between the working fluid and the surrounding. 


\section{A. A. El-Haroun, "Theoretical and Experimental Heat Transfer Analysis of a Flat Plate Collector ..."}

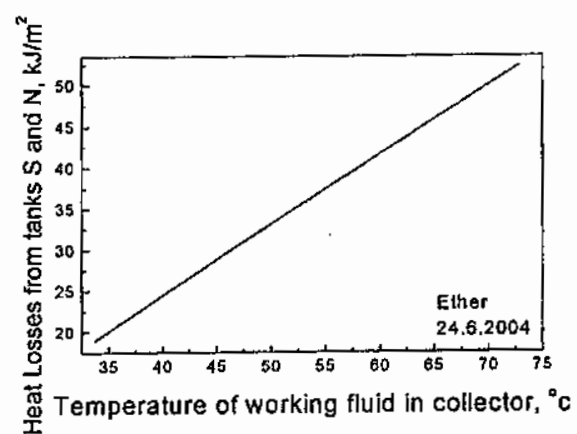

Figure 5 Change of heat losses from tanks $\mathrm{S}, \mathrm{N}$ with temp. of working fluid

Figures 6 and 7 show the effect of solar radiation intensity on heat losses from tanks $\mathrm{S}, \mathrm{N}$ and heat transferred to working fluid respectively for each of the two working fluids, Ether and Chloroform. There is a rise in each of these parameters with the increase in solar radiation intensity. The heat losses from tanks $\mathrm{S}, \mathrm{N}$ and heat transferred to working fluid for Ether are found to be little higher than the corresponding values for Chloroform at the same solar radiation intensity. The rise in solar radiation intensity results in an increase in working fluid temperature.

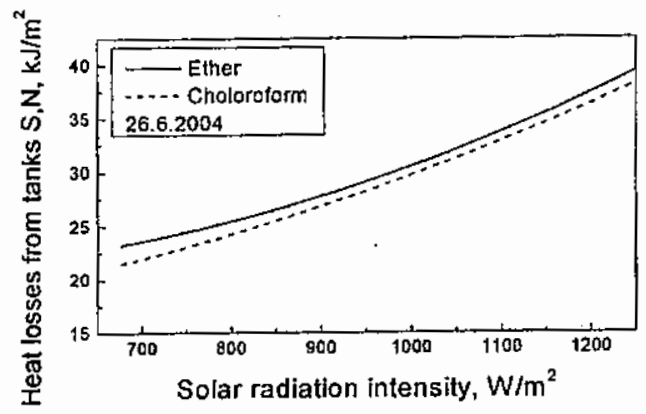

Figure 6 Effect of solar radiation intensity on heat losses from heat tanks S.N.

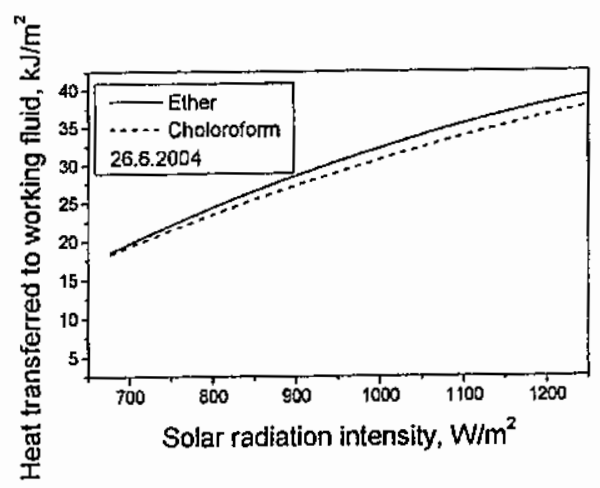

Figure 7 Effect of solar radiation intensity on heat transferred to working fluid
Figure 8 presents the variation of working fluid pressure with temperature for both Ether and Chloroform. One can see that, at the same working fluid temperature the pressure of Ether in the collection system is higher than the pressure of Chloroform. This will make Ether more suitable than Chloroform as working fluid in solar thermal pumps.

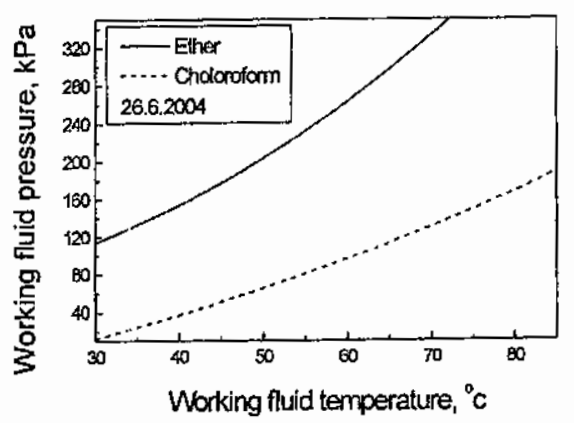

Figure 8 Variation of working fluid pressure with temperature

The variation of instantaneous system efficiency with time of the day is shown in Fig. 9. The instantaneous system efficiency is defined as the ratio of heat transferred to working fluid during certain interval $\mathrm{d} \theta$ to the total solar radiation intensity during the same period, as follows.

$$
\eta=d Q_{s} / I_{i} d \theta
$$

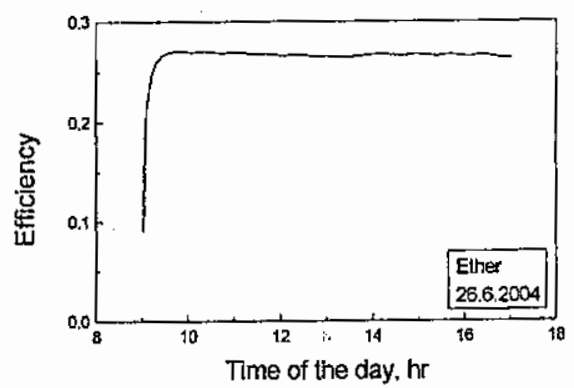

Figure 9 Variation of system efficiency with time of the day

From Fig. 9 one can see that, there is a sharp increase in system efficiency at the beginning of the day then the efficiency slightly decreases with time. At the beginning of the day, the temperature of working fluid and the heat transferred to working fluid increase sharply. This is the main reason for the sharp improvement in efficiency. With outflow of time the losses from the collection system and the decay in solar radiation intensity cause the efficiency to go down slightly. 


\section{A. A. El-Haroun, "Theoretical and Experimental Heat Transfer Analysis of a Flat Plate Collector ... "}

The above-predicted results were compared with some of the measured data. Figures 10 and 11 show the variation of both predicted and measured working fluid temperature and pressure with time respectively for Ether on 26 June. Both predicted and measured data having the same trend of change with time and the deviation between them is considerable.

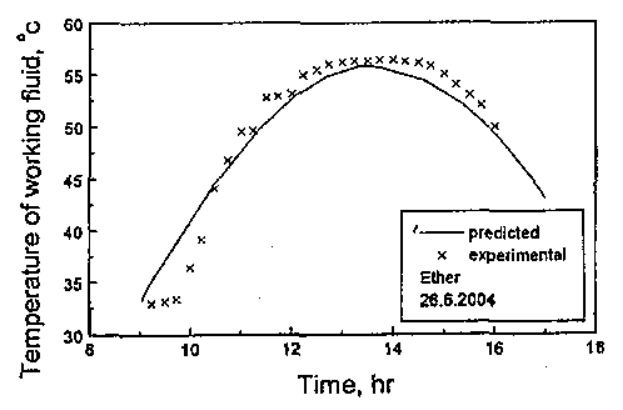

Figure 10 Calculated and measured working fluid temperature

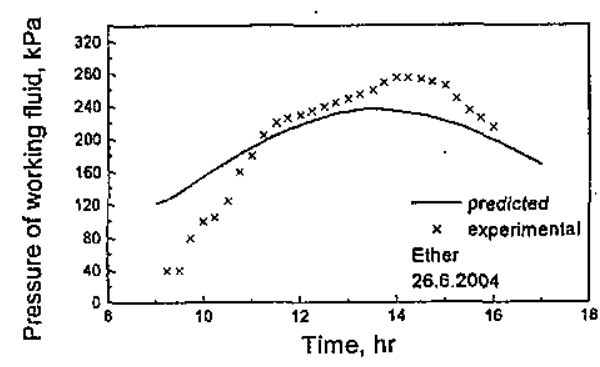

Figure 11 Calculated and measured working fluid pressure

\section{CONCLUSIONS}

In this work, a heat transfer analysis of solar thermal water pump using flat plate collector was carried out taking into consideration all heat losses in the collection system. Variations in temperature and pressure of working fluids with time as well as the variation of temperature at different points in collection system are predicted. The temperature and pressure of working fluids as well as the temperature at different points in the collection systems are measured and compared with the predicted values. Variations in collector efficiency with time are discussed.

It was found that, the working fluid and collector plate temperatures are increased with time of day till about solar noon then they decrease. There is also a rise in heat losses and heat transferred to working fluid with the rise in working fluid temperature or the rise in solar radiation intensity. A maximum theoretical efficiency for this system is expected to be $27 \%$ and is reached at the beginning of operation.
It was also found that, at the same working fluid temperature the working fluid pressure for Ether is higher than the pressure for Chloroform. This gives the indication that Ether will be more suitable than Chloroform for the operation of this pump.

The comparison between theoretical and measured data shows that, both theoretical and measured data have the same trend of change and the deviation between them is considerable.

\section{REFERENCES}

[1] Wong, Y.W.; Sumathy, K.: Solar thermal water pumping systems: a review; Renewable and Sustainable Energy Reviews, Vol. 3, pp. 185-217, 1999.

[2] Sumathy, K.: Experimental studies on a solar thermal water pump; Applied Thermal Engineering, Vol. 19, pp. 449-459, 1999.

[3] Kishore, V.; Gandhi, N.; Pathak, S.; et al: Development of a Solar Water Pump Prototype-An Indo-Swiss Experience; Solar Energy, Vol. 36, No. 3, pp. 257-265, 1986.

[4] Spindler, K.; Chandwalker, K. and Hahne, E.: Small Solar Thermal Water Pumping System; Solar Energy, Vol. 37, No. 1, pp. 69-76, 1996.

[5] Aghamohammadi, M.; Zarinchang, J. and Yaghoubi, M.: Performance of a Solar Water Pump in Southern Part of Iran; Proceedings of Sharjah Solar Energy Conference, Sharjah, United Arab Emirates, 19-22 Feb. 2001.

[6] Sumathy, K.; Venkatesh, A. and Sriramulu, V.: Heat Transfer Analysis of a Flat Plate Collector in a Solar Thermal Pump; Energy, Vol. 19, No. 9, pp. 983-991, 1994.

[7] Sumathy, K.; Venkatesh, A. and Sriramulu, V.: Thermodynamic Analysis of a Solar Thermal Water Pump; Solar Energy, Vol. 57, No. 2, pp. 155-161, 1996.

[8] Hewitt, G.: Heat Exchanger Design Handbook; Begell House, New York, 1998.

\section{NOMENCLATURE}

$A_{c} \quad$ collector area, $\mathrm{m}^{2}$

$\mathrm{C}_{1}$ Capacitance of the absorber plate, $\mathrm{J} / \mathrm{m}^{2} \mathrm{~K}$.

$\mathrm{C}_{2}$ Capacitance of the collector tubes, insulation and glass cover, $\mathrm{J} / \mathrm{m}^{2} \mathrm{~K}$.

$\mathrm{C}_{3} \quad$ Capacitance of tank $\mathrm{S}$ and $\mathrm{N}, \mathrm{J} / \mathrm{m}^{2} \mathrm{~K}$.

$\mathrm{dQ}$ absorbed energy per unit area of the collector, $\mathrm{J} / \mathrm{m}^{2}$.

$\mathrm{dQ}_{1}$ heat losses through tanks $\mathrm{S}$ and $\mathrm{N}, \mathrm{J} / \mathrm{m}^{2}$.

$\mathrm{dQ}_{\mathrm{s}}$ heat transfer to the fluid from the wall, $\mathrm{J} / \mathrm{m}^{2}$.

Gr Grashof number, --- 
A. A. El-Haroun, "Theoretical and Experimental Heat Transfer Analysis of a Flat Plate Collector ..."

$\mathrm{I}_{\mathrm{d}}$ diffuse radiation intensity, $\mathrm{W} / \mathrm{m}^{2}$.

$\mathrm{I}_{\mathrm{b}}$ total radiation intensity on a horizontal plane, $\mathrm{W} / \mathrm{m}^{2}$.

$I_{i}$ total intensity of radiation on an inclined surface, $\mathrm{W} / \mathrm{m}^{2}$.

$\mathrm{Nu}$ Nusselt number, ---.

$\mathrm{P}$ pressure of working fluid, $\mathrm{kPa}$.

Pr Prandtl number, ---.

$\mathrm{t}_{\mathrm{a}} \quad$ ambient temperature, ${ }^{\circ} \mathrm{C}$ $t_{f} \quad$ working fluid temperature at the end of period $\mathrm{d} \theta,{ }^{\circ} \mathrm{C}$

$t_{p}$ plate temperature, ${ }^{\circ} \mathrm{C}$

$t_{s}$ initial working fluid temperature, ${ }^{\circ} \mathrm{C}$

$t_{w} \quad$ wall temperature of the collector tubes, ${ }^{\circ} \mathrm{C}$

$U_{1}$ overall heat loss coefficient, $\mathrm{W} / \mathrm{m}^{2} \mathrm{~K}$.

$\mathrm{H}$ instantaneous system efficiency,- 